\title{
Cesium Cs 137
}

National Cancer Institute

\section{Source}

National Cancer Institute. Cesium Cs 137. NCI Thesaurus. Code C68812.

A radioactive isotope of cesium with an atomic mass of 139 and potential application in radiotherapy. Cesium Cs 137 is prevalent due to its spontaneous production, which occurs as a result of nuclear fission of other radioactive materials, such as uranium and plutonium. This radionuclide has a relatively long half-life, 30 years, and decays by emitting beta particles. Both Cs 137 and its metastable nuclear isomer, barium-137m, emit gamma radiation of moderate energy and so are used in sterilization procedures in the food industry or in hospital environments. 